Please cite this paper as follows:

Techno-economic comparison of a schedule-based and a forecast-based control strategy for residential photovoltaic storage systems in Germany (article)

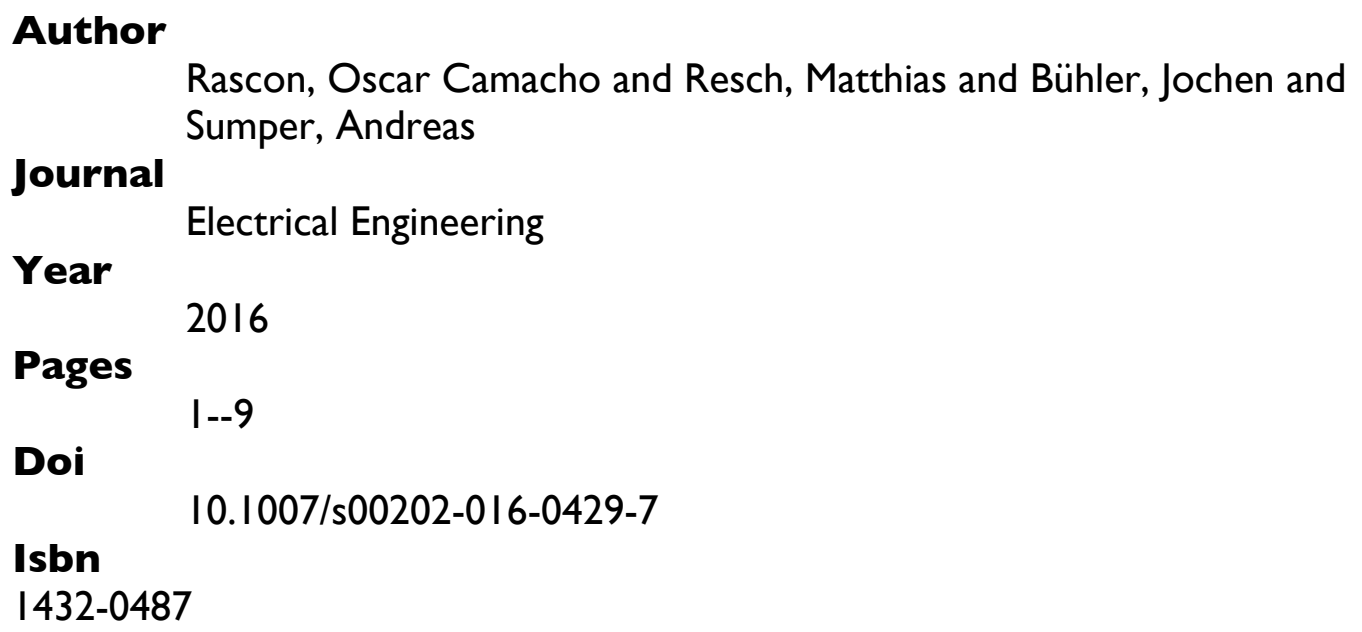

Author

Rascon, Oscar Camacho and Resch, Matthias and Bühler, Jochen and Sumper, Andreas

Journal

Electrical Engineering

Year

2016

Pages

I--9

Doi

10.1007/s00202-0|6-0429-7

Isbn

| 432-0487 


\title{
Techno-Economic Comparison of a Schedule-Based and a Forecast-Based Control Strategy for Residential Photovoltaic Storage Systems in Germany
}

Oscar Camacho Rascon ${ }^{1,2}$, Matthias Resch ${ }^{1,3, *}$, Jochen Bühler $^{1}$, Andreas Sumper $^{3}$

${ }^{1}$ Reiner Lemoine Institut gGmbH, Ostendstraße 25, 12459 Berlin, Germany

Phone +49 (0)30 5304 2013;

${ }^{2}$ Carl von Ossietzky Universität Oldenburg, Oldenburg, Germany

${ }^{3}$ UPC - Universitat Politècnica de Catalunya, Barcelona, Spain

*corresponding author: E-mail: matthias.resch@rl-institut.de

\begin{abstract}
In Germany the huge integration of small photovoltaic (PV) systems into the distribution grid during the past years lead to power quality issues due to the intermittent generation and reverse power flow in periods of low demand. In order to decrease this impact, different solutions are being investigated. The scope of this paper is to compare different strategies to control the charge power for residential PV storage systems for different load curves and to decide which might be the economically most profitable strategy. For this purpose, three different PV storage system control strategies were analyzed using MATLAB ${ }^{\circledR}$ to perform one year simulations on a minute step base. Measured input data from a PV system in the south of Germany were combined with four measured (extreme) load profiles and a standard load profile in order to conduct a sensitivity analysis. Performance indicators, such as selfconsumption ratio (SCR), self-supply ratio (SSR) and share of losses ratio (SLR), were used to compare the different control strategies. Furthermore, an economic analysis of these results was performed in order to obtain the profitability of every control strategy and determine the most profitable strategy, taking into account the household owner's benefits.
\end{abstract}

Keywords: residential PV storage, schedule-based, persistence forecast, economic evaluation. 


\section{Introduction}

The electrical power system in Germany has been changing for the past years; from a centralized energy system that supply power from big generating centers, to load distribution areas, to a distributed generation system where generators and loads are located along the MV (medium voltage) and LV (low voltage) areas. The amount of PV electricity generation in Germany has been increasing [1] along the years and led to an increase of PV penetration in the low voltage grid (around $70 \%$ of $38.5 \mathrm{GWp}$ installed in LV at the end of 2014) [2]. This huge PV penetration causes power quality issues on the grid. Ensuring the reliability of the system in conditions of high PV penetration is now one of the biggest challenges that the distribution system operators (DSO) have to face.

The most critical situation occurs at times of high power generation and low demand; this means that the feeders produce more energy than they consume. In order to avoid over-voltage and equipment over-loading issues in the system, traditional grid reinforcement is normally applied. The drawback of this grid planning procedure is the possibly large investment in infrastructure with a low utilization rate. Due to this high investment costs, a feed-in power restriction has been stipulated in order to mitigate possible issues [3]. As a result of this stipulated threshold, energy losses will occur, and so the profitability of PV systems will start to decrease.

Nowadays, with the decrease of the feed-in tariffs and the increase of the electricity prices in Germany, the use of self-generation of electricity became a new target to maximize the profitability of the PV systems. In order to increase the self-consumption, the German government introduced a financial incentive program [4] to push residential storage systems for grid connected PV smaller than $30 \mathrm{~kW}_{\mathrm{p}}$, instead of pure PV systems. The government incentive also came with a stipulated curtailment restriction for PV storage systems that applies to this program. For this reason, new operational concepts for the PV storage systems have been developed and analyzed in several studies $[5,6]$.

This paper builds upon a previous study [5], in which the two most promising strategies out of six control strategies for residential PV storage systems (RES) were identified by a qualitative approach. In this paper, three different control strategies for PV storage systems will be presented and analyzed in detail. The first one is the "state-of-the-art" algorithm [4] and is used as reference for the comparison of two promising storage control strategies of [5]. The second strategy uses a time interval to charge the storage system and the third uses a persistence forecast method. To quantify the performance of the algorithms and make them comparable, the performance indicators SCR, SSR and SLR as defined in [5] are used. In Section 2, the methodology describing the PV and load profiles used, the component models, and the implemented operation strategies of the RES is presented. The results of the simulation are presented and discussed in section 3. The main contribution of the work is the techno-economic comparison of a scheduled based and a prognosis based RES. The improvement based on the reference control strategy is quantified for both strategies using the performance criteria mentioned before along with a financial assessment in order to determine the most profitable strategy from a PV system owner`s point of view. To evaluate the robustness of the results a sensitivity analysis was conducted by using several (extreme) load profiles. Finally, the work is concluded in Section 4.

\section{Methodology}

In order to evaluate the control strategies performance, one year is simulated in one-minute steps with measured PV data and five different load profiles. This calculation is conducted for three different control strategies for residential PV storage systems. The aim of these strategies is to minimize the energy losses due to the feed-in limitation. The simulation model and the input parameters and operation strategies are presented in this section.

\subsection{Model}

For the evaluation of the three strategies, different MATLAB simulation programs have been developed. The general methodology followed is shown in Fig. 1. 


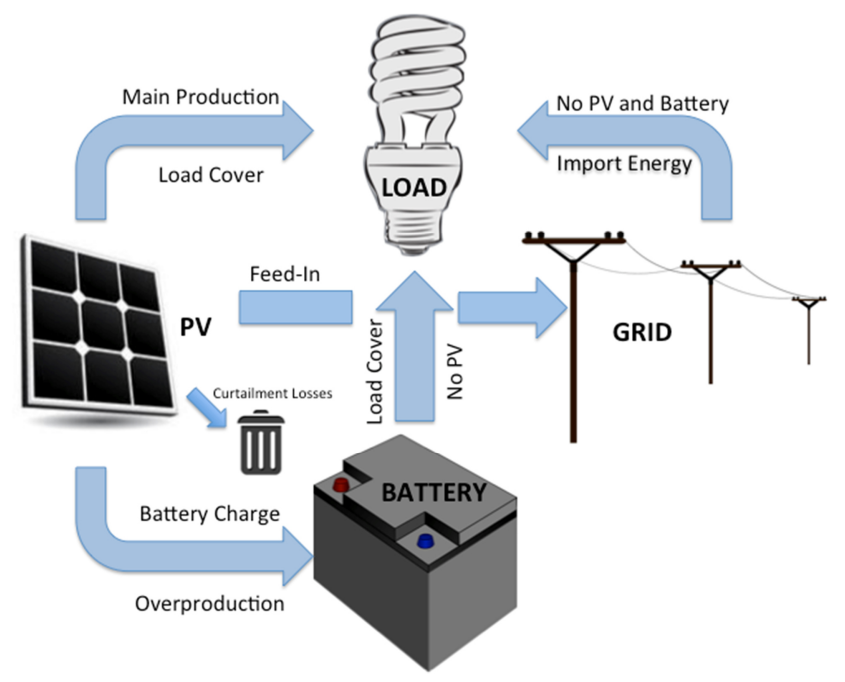

Figure 1. Schematic of the model used to evaluate the PV storage system.

\section{Load Cover}

The PV power $P_{P V}$ is used first to cover the load requirements in all available periods. In case the available PV power $P_{P V}$ cannot cover the requirement of load demand $P_{\text {load }}$, the system will use the energy stored in the battery $P_{b a t}$ to cover the load demand. If the energy in the battery is not sufficient and is fully discharged, the remaining load demand will be covered by importing power from the grid $P_{\text {import }}$.

\section{PV power utilization}

If the PV power $\mathrm{P}_{\mathrm{PV}}$ is higher than the load demand $P_{\text {load }}$, then the residual PV power $P_{\text {res }}$ is used to charge the battery (depending on the control specific features). For this study, the battery will never be filled-in directly with the grid power. If the battery is full, the residual PV power $P_{\text {res }}$ could be fed into the grid $P_{\text {feed_in }}$. In order to send the residual power $P_{\text {res }}$ to the grid, the amount of power has to be less than the curtailment threshold of $50 \%$ of the $P_{P V_{-}}$. If the residual power $P_{\text {res }}$ is above the curtailment threshold, the power to feed in $P_{\text {feed_in }}$ the grid will be limited to this threshold of $50 \% P_{P V_{-} p}$ and the remaining power will be wasted $P_{\text {curtailment }}$. The other way around, if the residual power $P_{\text {res }}$ is less than the curtailment threshold of $50 \%$ of $P_{P V_{-} p}$, the residual power $P_{\text {res }}$ will be sent to feed-in $P_{f e e d \_i n}$ the grid.

The simulation was conducted for one year in one-minute steps. The result values of $P_{\text {feed_in }}, P_{\text {import }}$, the state of charge of the battery (SOC), and $P_{\text {curtailment }}$ were obtained for every simulation step. With these values, the final behavior of each strategy was evaluated.

Equations (1) to (4) were used to obtain the values of the performance indicators previously mentioned.

$$
\begin{aligned}
E_{P V} & =\sum_{t=1 \mathrm{~min}}^{t=1 a} P_{P V} \cdot t \\
E_{\text {load }} & =\sum_{t=1 \mathrm{~min}}^{t=1 a} P_{\text {load }} \cdot t
\end{aligned}
$$

$$
\begin{gathered}
E_{P V \text { consumed }}=\sum_{t=1 \min }^{t=1 a}\left(P_{\text {load }}-P_{\text {import }}\right) \cdot t \\
E_{\text {losses }}=\sum_{t=1 \mathrm{~min}}^{t=1 a} P_{\text {curtailment }} \cdot t
\end{gathered}
$$

\subsection{PV Power}

The input data used for the PV time series is based on measured one-minute steps and in a few cases fifteen-minute steps. It is linearly interpolated to generate one-minute step values. These values were 
measured on a $107 \mathrm{~kW}_{\mathrm{p}}$ system in Unterrieden in southern Germany. The system has a tilt angle of $30^{\circ}$ and is facing south. The values where normalized to a $5 \mathrm{~kW}_{\mathrm{p}}$ system. This normalization was done taking into account an optimal ratio of PV system and storage system based on [7]. This results in a PV system size to annual load demand ratio of around $1 \mathrm{~kW} / \mathrm{MWh}$.

\subsection{Load}

For this study, five different load profiles were used in order to analyze different energy usage behaviors that might appear with households of the real LV grid. The profiles used are a German standard household profile H0 (SLP) and four extreme measured household behaviors from [8, 9]: day active profile (DA), night active profile (NA), heat pump user profile (HP), and air conditioning user profile (AC). These extreme household profiles were selected from a pool of 74 German household profiles for being the most extreme ones. The 15-min mean value of all 74 profile is nearly identical with the SLP, thus the SLP is taken as baseline [8]. The reason for choosing different load profile behaviors is to determine if with some specific consumption behaviors a difference of the benefits from one strategy to the other may appear, and to choose the most profitable strategy to be used on further analysis of the LV grid.

The characterization of the load profiles was done taking into account an annual load demand of $5 \mathrm{MWh}$. The samples for the SLP used for this analysis were taken in 15 min steps and then linearly interpolated to generate one-minute step values. The four extreme load profiles (DA, NA, HP and AC) were measured in 1-second steps and aggregated in 1-minute steps. In Fig. 2 the SLP load and the PV power generation data for an exemplary day is presented.

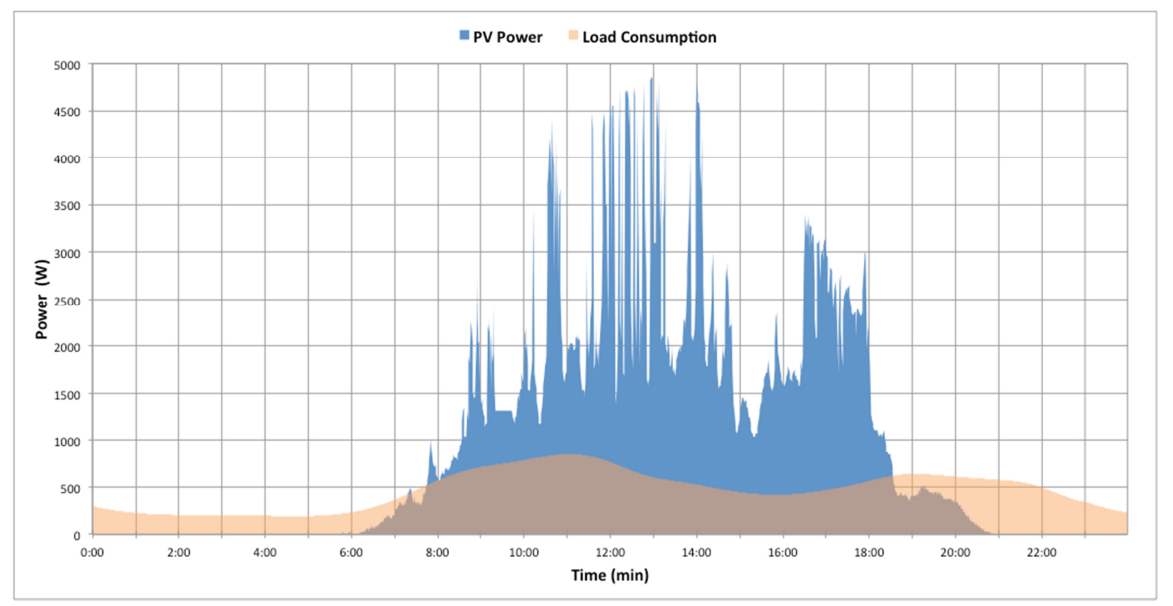

Figure 2. Load and PV power generation profile for exemplary day ( $6^{\text {nd }}$ of July).

\subsection{Battery model}

For this study, a lithium-ion battery system was chosen and is assumed to have a watt-hour efficiency of $95 \%$ and a constant bidirectional battery inverter efficiency of $94 \%$. This gives a round-trip efficiency of $84 \%$ for the battery and the inverter, according to [6]. The battery capacity is $5 \mathrm{kWh}$. For an optimal performance of the storage system, the SOC of the battery is fixed from $20 \%$ until $90 \%$ of the full capacity.

\subsection{Operation strategies}

The charge of a PV storage system can be done in different ways, these strategies may vary from one to the other in different parameters, but the aim of these changes is to obtain the best SCR with the minimum SLR in order to efficiently optimize the available power generated by the PV.

Here the three control algorithms analyzed in this paper:

1. Self-consumption (state-of-the-art) [5]. 
2. Schedule mode with constant charging power $[5,10]$.

3. Adaptive persistence forecast [11].

\subsubsection{Self-consumption (state-of-the-art) (SC)}

With this strategy, the main objective is to have the battery charged as soon as possible in order to use this energy later for own demand in periods with lack of PV power. This means that as soon as there is surplus of power available after load coverage, this power is used directly to charge the battery and when the battery is fully charged, the remaining power will go to the grid within the curtailment established limit. This strategy is the simplest one and is the most wide spread control applied in current PV storage systems.

In Fig. 3, the behaviors of this strategy are depicted on one exemplary day. This strategy ensures that the battery will be charged as a priority in order to increase the self-consumption ratio at maximum. This left the period of the day with the highest irradiance with only the possibility to feed the residual power in because the battery is already full. This means that with high irradiance, the power will surpass the feed-in limit, and the curtailment losses will be high as well.

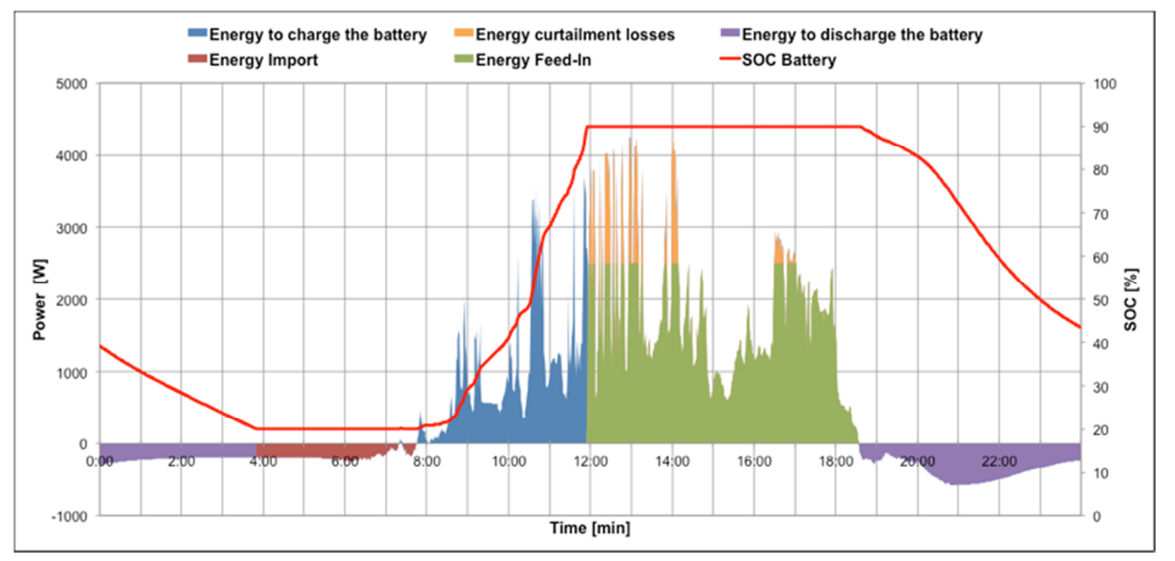

Figure 3. Self-consumption strategy. Power flow and battery SOC behaviour.

\subsubsection{Schedule mode with constant charging power (SMCCP)}

In this strategy, the power to charge the battery is calculated for every time step (1-min) in order to provide a smooth charging for a scheduled period of time (in this case from $9 \mathrm{am}$ to $3 \mathrm{pm}$ ). This period of time is used to charge the battery because it is the interval with the maximum probability of available power during the day and so the period with highest probability to exceed the curtailment limit.

The power to charge the battery $P_{\text {charge }}$ is given by:

$$
P_{\text {charge }}=\frac{Q_{b a t}}{t_{\text {st.ch }}-t_{\text {end.ch }}}
$$

Where $Q_{b a t}$ is the capacity of the battery available before it reaches full charge and $t_{\text {st.ch }}-t_{\text {end.ch }}$ is the remaining time available to charge the battery between the scheduled period of charge.

This type of control strategy will try to improve the system utilization in order to reduce the curtailment losses and increase as well the profitability of the investment. In Fig 4, the behavior of the SMCCP strategy on an exemplary day is shown. On days with low irradiance, this strategy will have the possibility of a not fully charged battery, because of the internal control algorithm that will look for a specific amount of $P_{\text {charge }}$ in every period of time $t_{\text {st.ch }}-t_{\text {end.ch. }}$. This means that if the $P_{\text {charge }}$ power calculated with the equation (5) is not available $\left(\mathrm{P}_{\text {res }}<\mathrm{P}_{\text {charge }}\right)$ in certain instants of time, the control algorithm will use the residual power $P_{\text {res }}$ on this period to charge the battery. This will lead to a remaining higher $Q_{b a t}$ in the next charging period and a lower remaining charging time $t_{\text {st.ch }}-t_{\text {end.ch }}$. Thus, if $\mathrm{P}_{\mathrm{res}}$ remains the same or decreases in the next interval of time, the battery will never be able to be fully charged.

In the other hand, on a high irradiance day, it can be observed that the schedule mode works perfectly well reducing the curtailment losses $\mathrm{P}_{\text {curtailment }}$ to the minimum. In order to use $\mathrm{P}_{\text {res }}$ as much as 
possible to charge the battery the control algorithm checks if the available $P_{\text {res }}$ on every period is enough to cover $\mathrm{P}_{\text {charge }}$ calculated with equation (5). If $P_{\text {res }}>P_{\text {charge }}$ then, the remaining residual power $P_{\text {res,rem }}$ will be compared with the curtailment limit. If $P_{\text {res,rem }}$ exceeds the curtailment threshold then it is limited. Some curtailment losses in the time after the charging period may occur on high irradiance days. This kind of schedule control will help to provide a smooth battery charging and reduce the curtailment losses if forecast data is not available.

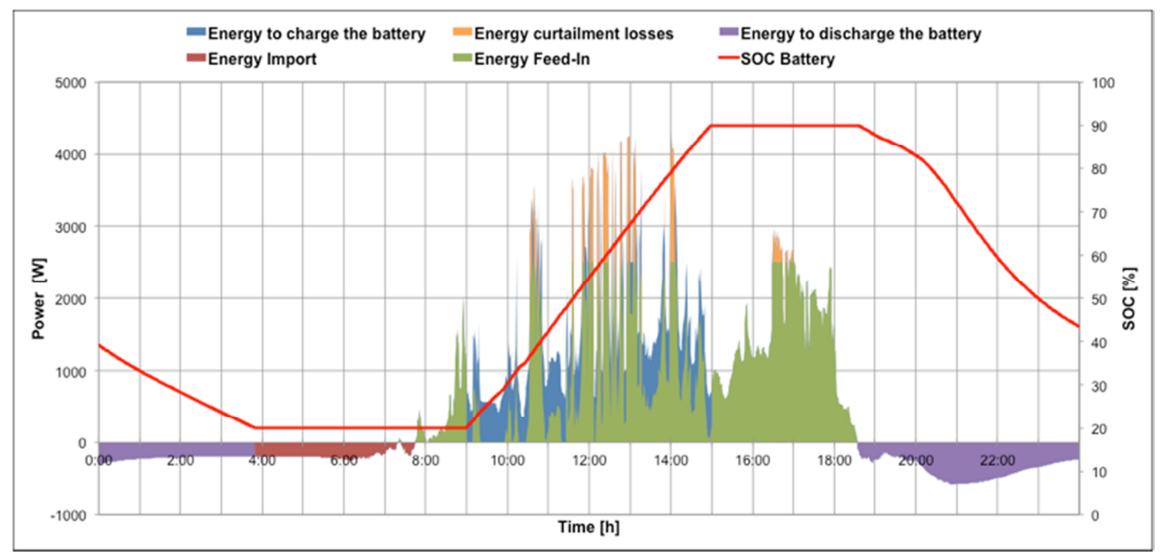

Figure 4. Schedule mode with constant charging power strategy. Power flow and battery SOC

\subsubsection{Adaptive persistence forecast (APF)}

This type of control strategy needs forecast information. Using this information for a more efficient charging algorithm, the amount of curtailment losses can be reduced and the SCR and SSR can be improved. Of course, the forecast accuracy plays a key role with this kind of strategies. Some strategies rely on external meteorological forecast systems, which in most cases increase the cost, as these services have to be paid and an additional communication infrastructure is necessary. A cost-free alternative is the use of an autonomous forecast like a persistence forecast. This type of forecast method assumes that the weather will remain constant in the near future and predicts the generation and load by using a comparison of measured data from the recent past. By forecasting the PV generation and load consumption, it is possible to improve the performance of this control strategy. The persistence forecast method used in this study is explained in detail in [6, 11]. A peculiarity of this strategy is that the PV power and load is determined by a mid-term forecast and the system is performing an adaptive adjustment of $P_{\text {charge }}$ for the battery every 15 -minute step. This means that if the forecast is not as accurate as expected, the system will adapt and adjust its behavior. In Fig. 5, we can observe the behavior of this strategy on the same exemplary day. It can be seen that the battery is charged during most of the radiation period, avoiding a high quantity of curtailment losses $P_{\text {curtailment }}$. As shown here, each of the strategies will have advantages and disadvantages as $[5,10,11]$ describe with more details.

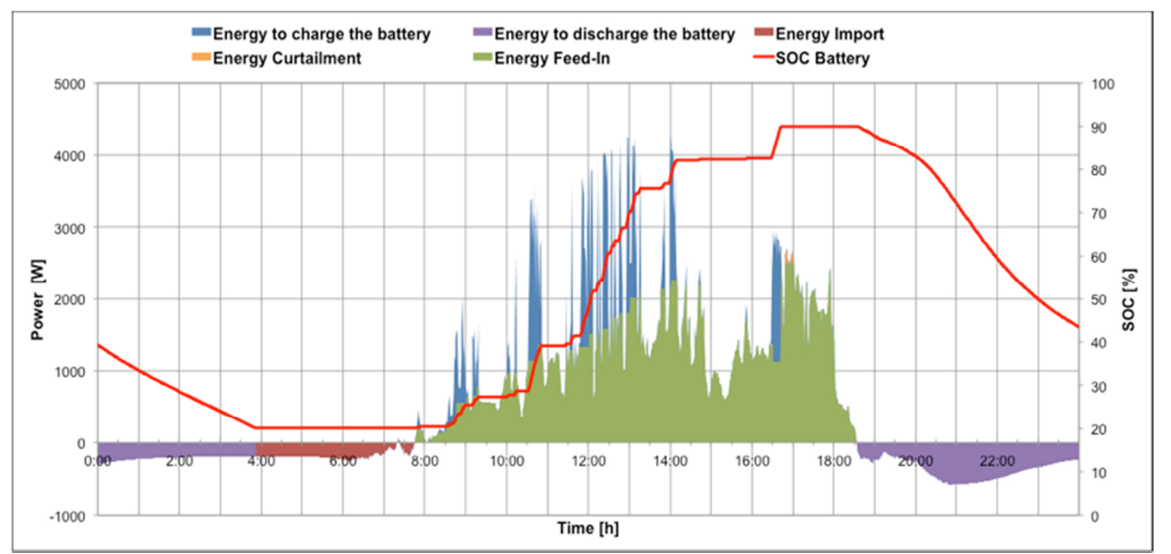

Figure 5. Adaptive persistence forecast strategy. Power flow and battery SOC behaviour. 
Taking into account the curtailment limit of $50 \%$ of $P_{P V_{-} p}$, a performance and economic evaluation of these strategies is shown in section 3.

\section{Results and discussion}

Hereafter, the results of the MATLAB simulations of the three control strategies for one-year on minute steps are presented. Furthermore, the performance indicators for each strategy, load variations and the economical evaluation are shown and discussed in this section.

\subsection{Power flow at point of common coupling for the different control strategies for RES}

In Fig. 6, the feed-in power at the point of common coupling (PCC) for each of the control strategies is depicted. The transparent horizontal plane shows the level of 50\% of feed-in curtailment. In Fig. 6(a), the curtailment losses due to the lack of battery storage are highest. In Fig. 6(b), the SC strategy is depicted. It can be observed, that on morning periods there is no power flowing to the grid, this means that the power is being stored, but just after full charge the power will start to flow again to the grid and the curtailment losses will start to increase. The SMCCP strategy is depicted in Fig. 6(c), the power will flow during the whole PV generation period and the curtailment is effectively reduced due to the restriction of the charging period. Finally, Fig. 6(d) shows the APF strategy. As in Fig. 6(c) the power is fed-in during the generation period and the intelligent persistence forecast control helps to minimize the losses even further than with SMCCP. The amount of yearly reduction for each of the control strategies will be presented in the following subsection.

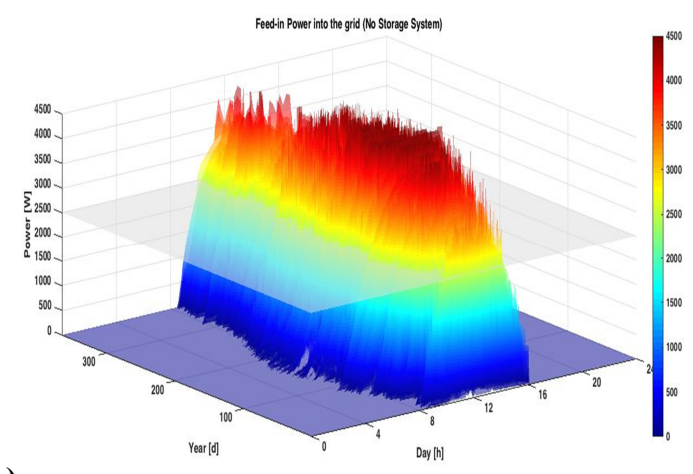

(a)

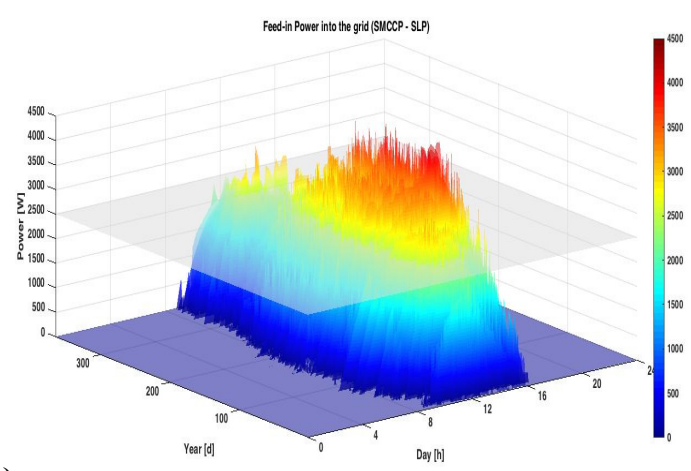

(c)

Figure 6. Power flow at the PCC. (a) No storage system, (b) SC strategy, (c) SMCCP strategy, (d) APF strategy.

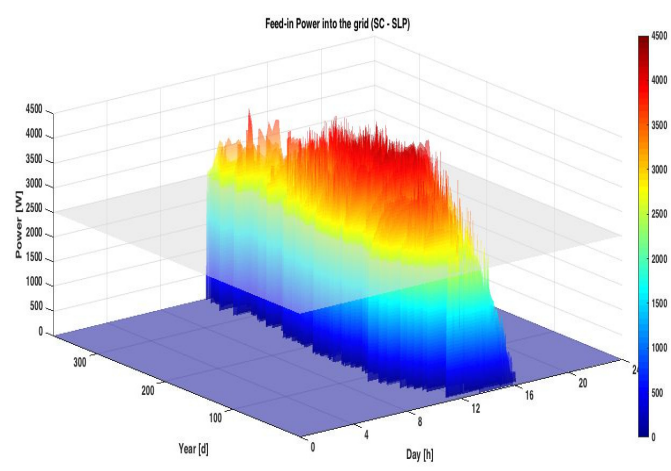

(b)

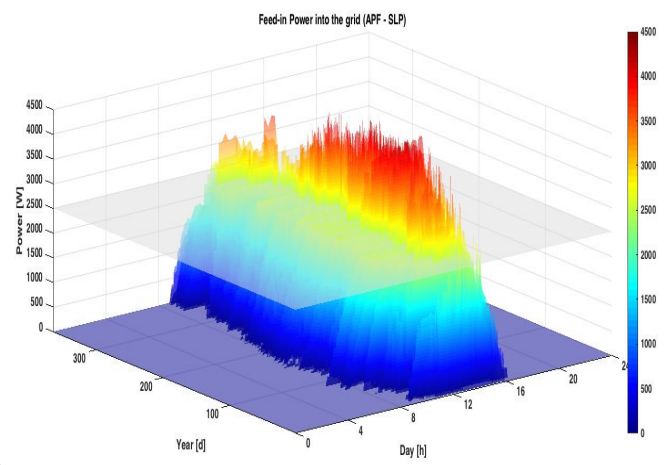

d)

\subsection{Self-consumption ratio (SCR)}

In Fig. 7, the results the three strategies and the five different load profiles are shown. It can be observed that the SC strategy maximizes the use of PV in order to have the battery charged as soon as possible. The APF is always less than $1 \%$ below SC strategy, which means that the adaptive function is almost getting the maximum possible SCR. 


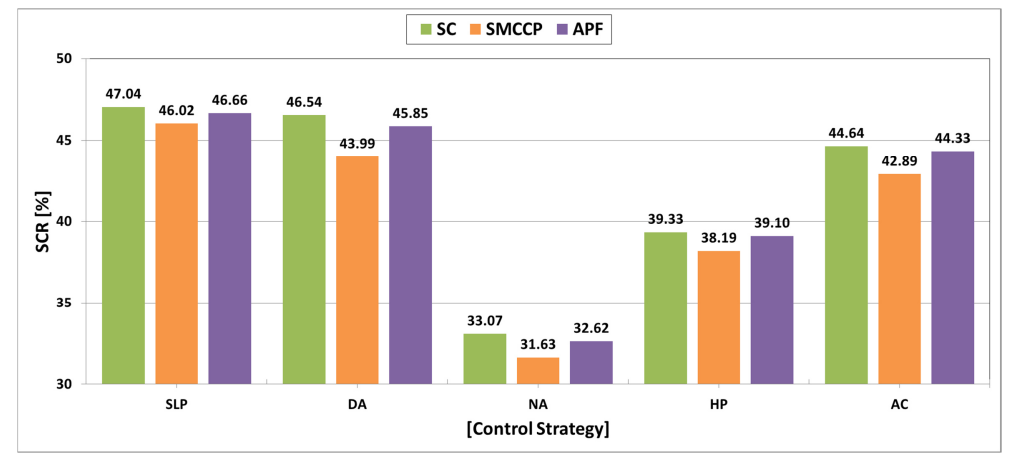

Figure 7. Self-consumption ratio. Three control strategies using five different load profiles were evaluated.

\subsection{Self-supply ratio (SSR)}

Fig. 8 shows that the SC strategy has the highest values within all the different load profiles. The APF, again, is the strategy that follows the gains of SC.

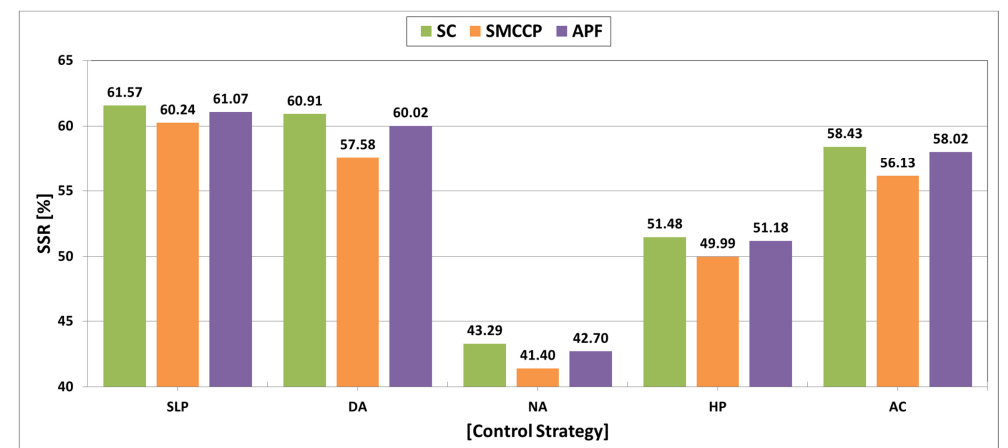

Figure 8. Self-supply ratio. Three control strategies using five different load profiles were evaluated.

\subsection{Share of losses ratio (SLR)}

The SLR is shown in Fig. 9. For the SC control, the losses are higher, because the battery is fully charged too fast during high irradiance periods. With the APF strategy, the losses are reduced around $50 \%$. This means that the forecast is quite accurate and the adaptive method is working well. The main drawback of this strategy is when the day ahead is not at all similar to the previous day, then the losses will increase and the adaptive part will sometimes not react as fast as required. The ideal adaptive speed is also evaluated in [6]. With the SMCCP control, the losses are reduced by more than 5\% with all the load profiles $(>50 \%)$. This difference shows that the implementation of a SMCCP control strategy will help to reduce energy losses for the system due to a more optimized charging control method.

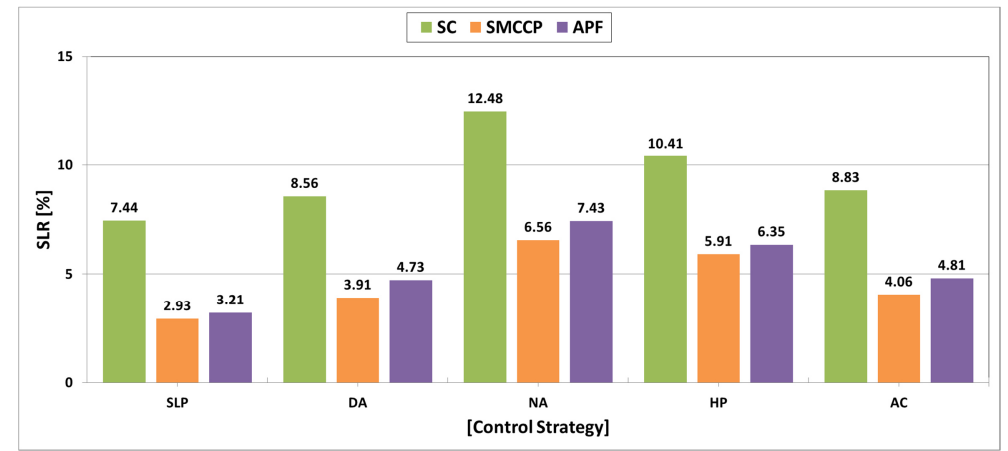

Figure 9. Share of losses ratio. Three control strategies using five different load profiles were evaluated. 
In this subsection, it has been shown that the APF and SMCCP control strategies compared to the SC will have a greater impact on the SLR of the PV storage system. Nevertheless, the impact on the SCR and SSR is not very high. This means that the control strategy used on the PV storage system will lead to an improvement for the household owners in terms of quantity of energy feed-in to the grid without compromising a good management of the storage system and at the same time respecting the curtailment limit.

\subsection{Economic analysis}

In this subsection, the economic assessment which analyses the impact on the implementation of SMCCP or APF control strategies versus a system that only has a SC strategy implemented is presented. As shown before, the implementation of a different control strategy than SC will cause a decrease in the SCR, SSR, and the SLR. This evaluation will determine the economic improvement that will affect the profit of the system owner. The following assumptions have been used: Feed-in tariff of $€ 0.1231$ and a electricity price of $€ 0.2881$ [12, 13]. The economic evaluation is highly sensitive on specific prices at the time of the evaluation.

In order to determine the annual profit (AP) for the SMCCP and APF strategy compared to SC strategy, the following equation (6) has been used [11]:

$$
\Delta A P=\left(\Delta S L R * E_{P V}+\frac{\Delta S S R}{\eta_{\text {Bat }}} * E_{\text {load }}\right) * f t-\Delta S S R * E_{\text {load }} * e p
$$

Where:

$\triangle S L R$... Change of SLP versus SC strategy.

$E_{P V} \ldots$ Total energy generated.

$f t$... Feed-in tariff.

$\triangle S S R$... Change of SSR versus SC strategy.

$E_{\text {load }}$... Total load demand.

ep ... Electricity price.

In Fig. 10, the results of the AP calculations are presented. The SC strategy was used as reference for the comparison for the SMCCP and APF strategies. This means that the values presented here are the AP increase for the implementation of a specific PV storage control strategy. It can be seen that the APF strategy has the best annual profit (AP) in all evaluated load profiles. Thus, it can be determined that the best control strategy for a PV storage system is the APF.

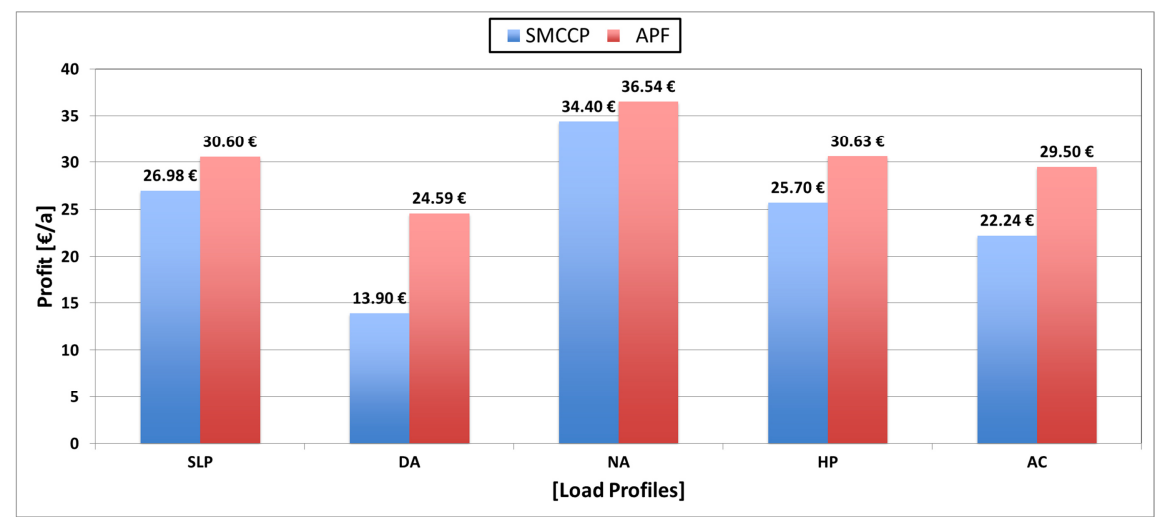

Figure 10. Annual profit evaluation. Two control strategies using five different load profiles were evaluated.

\section{Conclusion}

As self-consumption with PV storage systems becomes more attractive every day as a profitable business case, it is important to examine different operation strategies. They should be grid-supportive, in this case by applying a curtailment limit of $50 \%$ of the installed nominal PV power, and at the same time be profitable for the battery owner. Two autonomously operating control strategies, which fulfill these two aims by relying entirely on locally measured values were investigated and compared with the 
state-of-the-art strategy. By conducting a sensitivity analysis using different extreme load profiles, it was shown that the adaptive persistence forecast control strategy is the one with the best technical and economic performance, taking into account the system utilization and the owner's economic benefits. For all five load profiles, the APF shows higher values than the SMCCP. Although the SLR is higher for the APF than for the SMCCP, the annual profit is higher for every load profile used. The control optimization of PV storage systems apart from the owner benefits may lead to an increase of PV penetration in LV grids without the need of expensive investments by the DSO to the actual grids. Future studies could examine reactive and active power control strategies by implementing the adaptive persistence forecast for residential energy storages to quantify the increased hosting capacity for PV.

\section{Acknowledgements:}

This work was supported by the German Federal Ministry of Economics and Technology (BMWi) and the Projektträger Jülich GmbH (PTJ) within the framework of the project "SmartPowerFlow" (FKZ0325523A). We thank also the joint research partners from the SMA AG, the Lechwerke Verteilnetze GmbH (LVN) as well as the Younicos AG for their great support. The authors gratefully acknowledge the contributions of the research group Solar Storage Systems of the HTW Berlin.

\section{References}

[1] BDEW Bundesverband der Energie und Wasserwirtschaft. „Erneuerbare Energien und das EEG: Zahlen, Fakten, Grafiken (2016), Anlagen, installierte Leistung, Stromerzeugung, EEG Auszahlungen, Marktintegration der Erneuerbaren Energien und regionale Verteilung der EEG Anlagen“, Berlin, 18.Feb.2016.

[2] Harry Wirth, Aktuelle Fakten zur Photovoltaik in Deutschland (Date 7.1.2015), Fraunhofer ISE.

[3] Gesetz für den Ausbau erneuerbarer Energien (Erneuerbare-Energien-Gesetz - EEG 2014).

[4] K.-P. Kairies, D. Magnor, and D. U. Sauer, 'Scientific Measuring and Evaluation Program for Photovoltaic Battery Systems (WMEP PV-Speicher)', Energy Procedia, vol. 73, pp. 200-207, Jun. 2015.

[5] M. Resch, B. Ramadhani, J. Bühler, A. Sumper, Comparison of control strategies for residential PV storage systems, in: 9th International Renewable Energy Storage Conference and Exhibition (IRES 2015), Messe Düsseldorf, 9. - 11. March 2015.

[6] J. Weniger, J. Bergner, and V. Quaschning, "Integration of PV power and load forecasts into the operation of residential PV battery systems," in 4th Solar Integration Workshop, 2014, pp. 383390.

[7] J. Weniger, T. Tjaden, and V. Quaschning, "Sizing and grid integration of residential PV battery systems”, 8th International Renewable Energy Storage Conference and Exhibition (IRES), (2013).

[8] T. Tjaden, J. Bergner, J. Weniger and V. Quaschning, "Repräsentative elektrische Lastprofile für Wohngebäude in Deutschland auf 1-sekünde Datenbasis", Forschungsgruppe Solarspeichersysteme, HTW Berlin - University of Applied Sciences, Berlin, Germany, November 2015.

[9] J. Weniger, J. Bergner, T. Tjaden, V. Quaschning, "Dezentrale Solarstromspeicher für die Energiewende", HTW Berlin - University of Applied Sciences, Berlin, Germany, June 2015.

[10] C. Williams, J. Binder, M. Danzer, F. Sehnke, and M. Felder, "Battery charge control $\square$ schemes for increased grid compatibility of decentralized PV systems," 28th Eur. Photovolt. $\square$ Sol. Energy Conf. Exhib., (2013).

[11] J. Bergner, J. Weniger, T. Tjaden, and V. Quaschning, "Feed-in Power Limitation of GridConnected PV Battery Systems with Autonomous Forecast-Based Operation Strategies," in 29th European Photovoltaic Solar Energy Conference and Exhibition, Amsterdam, 2014.

[12] BDEW Bundesverband der Energie- und Wasserwirtschaft e.V., "Erneuerbare Energien und das EEG: Zahlen, Fakten, Grafiken (2015)”, Berlin, 11. Mai 2015.

[13] Bundesnetzagentur, "Bestimmung der Förderssätze für Fotovoltaikanlagen § 31 EEG 2014 für die Kalendermonate Oktober 2015, November 2015 und Dezember 2015”. 